\title{
Menentukan Prioritas RKPDes (Rencana Kerja Pembangunan Desa) Dengan Metode Simple Additive Weighting
}

\author{
Determining Priority of RKPDes (Work Plan of Village Development) Using Simple Additive \\ Weighting
}

\section{Lulu Muhamad Ulumudin ${ }^{1}$, Ozzi Suria ${ }^{2}$}

\author{
${ }^{1,2}$ Program Studi Sistem Informasi, Fakultas Teknologi Informasi, Universitas Mercu Buana Yogyakarta \\ J1. Wates Km. 10 Yogyakarta, 55753, Indonesia \\ Email: lulumuhamad27@gmail.com¹, ozzisuria@mercubuana-yogya.ac.id ${ }^{2}$
}

\begin{abstract}
ABSTRAK
RKPDes adalah program pemerintah yang digunakan untuk proses pembangunan suatu desa agar lebih maju dalam segala hal. Namun kenyataannya, di desa Ciburuy Kecamatan Bayongbong Garut Jawa Barat dalam menentukan usulan rencana kerja pembangunan desa masih menggunakan cara musyawarah tanpa adanya suatu pertimbangan yang ditentukan sehingga tidak mendapatkan hasil yang sesuai dan tepat sasaran. Penelitian ini mencoba untuk membuat sebuah sistem informasi berbasis komputer yaitu sistem pendukung keputusan (SPK) yang dapat membantu proses pengambilan keputusan dengan menggunakann metode Simple Additive Weighting (SAW) dalam menentukan Rencana Kerja Pembangunan Desa (RKPDes) dengan mempertimbangkan beberapa kriteria yang sudah ditentukan yaitu volume, manfaat, waktu pelaksanaan dan anggaran. Berdasarkan hasil dari penelitian yang sudah dilakukan dengan memanfaatkan metode Simple Additive Weighting (SAW) didapatkan hasil yang sama dengan tingkat akurasi sebesar $75 \%$ dari seluruh data RKPDes tahun 2017 yang sudah direalisasikan di desa Ciburuy.
\end{abstract}

Kata kunci: Alternatif, Desa Ciburuy, Kriteria,RKPDes, Sistem Pendukung Keputusan, Simple Additive weight.

\begin{abstract}
The RKPDes (Work Plan of Village Development) is a government program that is used for the development process of a village. The method to determine the village's development work plan proposal in Ciburuy Village, Bayongbong District, Garut, West Java, is still using the discussion or conference without any determined consideration, thus there is no suitable and objective result that is right on target. This research tries to create an information system, that is the Decision Support System, which is able to help the process of decision making by using Simple Additive Weighting $(S A W)$ method. This method is used determine the RKPDes by considering some criteria. There are the volume, benefit, execution time, and budget. The result of this research by utilizing the SAW method, the system can provide results which were same with the accuracy of 75\% of all 2017 RKPDes data which has been done in Ciburuy Village.
\end{abstract}

Keywords: Alternative, Ciburuy Village, Criterion, RKPDes (Work Plan of Village Development), Simple Additive Weighting, DSS (Decision Support System).

\section{PENDAHULUAN}

Pemerintah desa beserta lembaga desa merumuskan program pembangunan desa atau dikenal dengan istilah RKPDes (Rencana Kerja Pembangunan Desa) sebagai penjabaran RPJMDes (Rencana Pembangunan Jangka Menengah Desa) (Sumarna, 2016). Dalam hal ini, untuk menentukan rencana kerja pembangunan pada suatu desa masih memiliki beberapa masalah dikarenakan tidak adanya titik temu dalam hal penentuan pembangunan apa yang harus diprioritaskan. Pemerintah desa masih melakukan penentuan keputusan dengan 
cara musyawarah dengan para masyarakat desa dengan tidak adanya aspek yang pasti yang bisa dijadikan bahan pertimbangan. Studi kasus yang diteliti dalam penelitian ini adalah penentuan usulan rencana kerja pembangunan desa (RKPDes) di desa Ciburuy Kec. Bayongbong Garut provinsi Jawa Barat, dikarenakan dalam menentukan usulan rencana kerja pembangunan desa (RKPDes) masih mengandalkan cara bermusyawarah mengumpulkan para masyarakat desa dan hanya didasari oleh pendapat dan argumen mayarakat desa saja.

Dalam penelitian ini, peneliti mencoba untuk memberikan solusi untuk mengurangi permasalahan tersebut dengan cara membangun sebuah sistem informasi berbasis komputer yang dapat membantu memberikan solusi bagi pihak staff kantor desa Ciburuy dalam menentukan prioritas RKPDes berdasarkan beberapa pertimbangan yang telah ditentukan oleh pihak kantor desa. Pembuatan sistem pendukung keputusan ini menggunakan metode Simple Additive Weighting sebagai metode perhitungan dalam pemecahan masalah, metode ini memiliki konsep dasar mencari penjumlahan terbobot dari rating kinerja pada setiap alternatif pada semua atribut. Sistem Pendukung Keputusan (SPK) ini diharapkan bisa menjadi alat bantu bagi instansi/lembaga terkait untuk menyediakan informasi, membimbing, memberikan prediksi agar dapat melakukan pengambilan keputusan dengan lebih baik (Riadi, 2013).

\section{TINJAUAN PUSTAKA}

Dalam penelitian yang berjudul "Sistem Pendukung Keputusan Penentuan Skala Prioritas Pembangunan Menggunakan Metode Promethee Pada Desa Ayula Kecamatan Randangan Kabupaten Pohuwato Provinsi Gorontalo" dilakukan oleh Jorry Karim, penulis melihat permasalahan yang sering terjadi di desa yaitu tahap pembangunan di desa harus mempertimbangkan skala prioritas dan unsur keadilan, serta belum adanya sistem pendukung keputusan untuk penentuan skala prioritas pembangunan pada desa Ayula kecamatan Randangan dan juga sistem yang digunakan saat ini belum terkomputerisasi secara maksimal. Oleh karena itu, pada penelitian ini dirancang sebuah sistem pendukung keputusan untuk menentukan prioritas pembangunan. Metode yang digunakan adalah salah satu metode penyelesaian masalah MCDM yaitu PROMETHEE yang merupakan salah satu metode penentuan urutan atau prioritas. Sistem ini dirancang menggunakan bahasa pemrograman PHP dengan Database MySQL, untuk membuatkan sebuah sistem pendukung keputusan baru yang berbasis komputerisasi yang merupakan salah satu alternatif yang baik dengan mengedepankan efektifitas dan efisien dalam penentuan prioritas pembangunan. (Karim, 2018).

Dalam penelitian yang dilakukan oleh Taqwa Harigunna dan arinta okviantari yang berjudul "Penentuan Prioritas Program Kerja Pada Anggaran Pendapatan dan Belanja Desa Menggunakan Metode Analytical Hierarchy Process" penulis merancang sebuah sistem pendukung keputusan yang memerlukan pemberian nilai bobot untuk setiap alternatif program kerja, kemudian dilanjutkan dengan perangkingan yang akan menyeleksi alternatif yang diberikan. Agar pemilihan alternatif lebih sistematis maka diperlukan sebuah sistem penunjang keputusan. Salah satu metode pengambilan keputusan adalah metode Analytical Hierarchy Process (AHP). Penelitian ini bertujuan untuk menerapkan sistem pendukung keputusan dengan metode AHP pada penentuan prioritas program kerja APBDesa berbasis web. (Harigunna \& Arinta, 2017).

Dalam penelitian yang dilakukan oleh Agung Nilogiri dan kawan-kawan yang berjudul "Sistem Pendukung Keputusan Menentukan Prioritas Lokasi Perbaikan Jalan Menggunakan Metode AHP”, Peningkatan jumlah lokasi jalan berkaitan dengan jumlah perbaikan jalan yang harus dilakukan. Kondisi ini mengakibatkan perusahaan kesulitan dalam menentukan prioritas lokasi perbaikan jalan. Penelitian ini bertujuan untuk menentukan lokasi perbaikan jalan yang terbaik dari beberapa alternatif posisi lokasi perbaikan jalan dengan cara memberikan posisi peringkat alternatif di beberapa lokasi berdasarkan kriteria seleksi jalan yang telah ditetapkan. Untuk menentukan posisi lokasi terbaik berdasarkan banyak pertimbangan kriteria diantaranya meliputi kondisi jalan, volume, pengaruh dan biaya. dimana kriteria tersebut dapat diukur secara kuantitatif dengan metode Analytical Hierarchy Process (AHP) untuk memudahkan pihak Pekerjaan Umum (PU) Bina Marga dalam menentukan lokasi perbaikan jalan terbaik terhadap berbagai jenis 
masalah yang akan di analisa. Pengujian ini dilakukan terhadap 40 dataset jalan tahun 2009. Dengan sistem ini akan membantu pihak Bina Marga untuk mengambil keputusan secara lebih subjektif. (Nilogiri \& Arifianto, 2016).

Pada penelitian yang dilakukan oleh Rubiati Rofiqo pada tahun 2009 yang berjudul "Sistem Pendukung Keputusan Menentukan Lokasi Pembangunan Perumahan Dengan Metode Analitycal Hierarchy Process (AHP)" tentang penelitian menentukan lokasi pembangunan perumahan dengan metode Analytic Hierarchy (AHP) di kota Pekanbaru Riau yang pada saat itu sedang mengalami perubahan fungsi lahan karena pertumbuhan penduduk dengan mempertimbangkan beberapa kriteria seperti kondisi lahan, infrastruktur, sosial \& ekonomi, serta ketersediaan lahan yang kemudian dihitung dengan metode SPK Analytic Hieararchy Process Kemudian hasil dari pengujian dengan metode ini adalah berupa beberapa alternatif lokasi pembangunan perumahan yang layak untuk diprioritaskan karena memiliki nilai hasil perhitungan yang paling tinggi diantara nilai alternatif lainnya (Rufiqo, 2009).

Mardheni Muhammad melakukan penelitian pada tahun 2017 dengan judul "Implementasi Metode Simple Additive Weighting (Saw) Pada Sistem Pendukung Keputusan Dalam Menentukan Prioritas Perbaikan Jalan " menerangkan bahwa jalan adalah infrastruktur yang sering dilalui oleh masyarakat. Dalam melakukan perencanaan perbaikan terdapat kendala salah satunya adalah sulit menentukan prioritas perbaikan jalan dengan keterbatasan dana dari pusat. Pada penelitian yang dilakukan data survei diinputkan oleh karyawan berdasarkan data lapangan diproses menggunakan metode Simple Additive Weighting (SAW) dengan menentukan kriteria-kriteria dalam pengambilan keputusan yakni, tingkat kerusakan jalan, kebutuhan lokasi (fasilitas umum), perkiraan biaya, kontruksi jalan, dan masa pemeliharaan. Hasil pengujian menunjukkan bahwa metode Simple Additive Weighting (SAW) mampu menghasilkan rekomendasi prioritas perbaikan jalan berdasarkan kriteria yang dibutuhkan (Muhammad, Safriadi, \& dkk, 2017).

Pada penelitian yang dilakukan oleh Anggi Triwa Bahari, dkk pada tahun 2017 yang berjudul "Sistem Pendukung Keputusan Penentuan Lokasi Bimbingan Belajar
Dengan Metode Weighting Product (WP) Berbasis Webgis" tentang penentuan lokasi cabang bimbingan belajar untuk memberikan lokasi cabang bimbingan belajar yang baru. Penentuan saran lokasi terbaik ini dipertimbangkan berdasarkan beberapa kriteria seperti jarak ke jalan utama, jarak ke pusat perbelanjaan, jarak ke sekolah dan tingkat kepadatan penduduk yang dihitung dengan metode Weighting Product.

Kemudian hasil dari perhitungan ini berupa rating beberapa alternatif lokasi terbaik yang diimplmentasikan pada sebuah aplikasi yang berbasis peta (Geographic Information System). Penelitian ini bertujuan untuk membangun sebuah sistem pendukung keputusan yang berfungsi sebagai alat bantu bagi pengelola lembaga bimbingan belajar dalam pengambilan keputusan pada proses pemilihan lokasi bimbingan belajar (Bahari \& dkk, 2017).

Pada penelitian yang berjudul "Sistem Pendukung Keputusan Untuk Menentukan Lokasi Perumahan Di Kabupaten Pringsewu Menggunakan Metode Weighting Product" dilakukan Amel Dhea Saputri dan Oktafianto untuk menentukan lokasi perumahan di kabupaten Pringsewu karena Pemilihan lokasi perumahan yang strategis baik dari segi geografi maupun ekonomi sangat penting untuk dilakukan agar perumahan yang dibangun akan memiliki nilai guna dan nilai jual yang tinggi dan memberikan kepuasan pada konsumen serta untuk memenuhi kebutuhan perumahan yang dari tahun ke tahun semakin bertambah seiring meningkatnya jumlah penduduk. Untuk menentukan lokasi perumahan yang diharapkan maka ditentukan beberapa kriteria diantaranya jarak kejalan utama, jarak ke pusat perbelanjaan (pasar), jarak dengan pusat pendidikan (sekolah) dan kepadatan penduduk sekitar lokasi sebagai bahan acuan untuk menentukan saran lokasi perumahan terbaik (Saputri \& Oktafiano, 2017).

Metode Simple Additive Weighting (SAW) sering juga dikenal istilah metode penjumlahan terbobot. Formula untuk melakukan normalisasi adalah seperti pada Persamaan 2.1. 


$$
\mathrm{R}_{\mathrm{ij}}= \begin{cases}\frac{x_{i j}}{\operatorname{Max}_{i j}} & \begin{array}{l}
\text { Jika } \mathrm{j} \text { adalah atribut keuntungan } \\
\text { (benetif) }
\end{array} \\
\frac{\operatorname{Min}_{i j}}{x_{i j}} & \text { Jika } \mathrm{j} \text { adalah atribut biaya (cost) }\end{cases}
$$

Keterangan:

$\mathrm{R}_{\mathrm{ij}}=$ Normalisasi baris ke $\mathrm{i}$ dan kolom ke $\mathrm{j}$.

$\mathrm{X}_{\mathrm{ij}}=$ Nilai kriteria baris ke $\mathrm{i}$ dan kolom ke $\mathrm{j}$.

Min/Max $X_{\mathrm{ij}}=$ Nilai minimal/ maksimal pada masing-masing kriteria.

Variabel $\mathrm{R}_{\mathrm{ij}}$ adalah rating kinerja ternormalisasi dari alternatif Ai pada atribut $\mathrm{Cj} ; \mathrm{i}=1,2, \ldots \mathrm{m}$ dan $\mathrm{j}=1,2, \ldots, \mathrm{n}$.

Untuk nilai preferensi untuk setiap alternatif (Vi) seperti Persamaan 2. 2.

$V_{i}=\sum_{j=1}^{n} W_{j} r_{i j}$

Keterangan:

$\mathrm{V}_{\mathrm{i}}=$ Nilai hasil baris ke $\mathrm{i}$.

$\mathrm{W}_{\mathrm{j}}=$ Bobot yang pada masing-masing kriteria.

$\mathrm{R}_{\mathrm{ij}}=$ Nilai normalisasi dari baris i dan kolom $\mathrm{j}$.

Nilai Vi yang lebih besar mengidentifikasikan bahwa alternatif Ai lebih terpilih. Langkahlangkah dari metode SAW adalah:

1. Menentukan kriteria-kriteria yang akan dijadikan acuan dalam pengambilan keputusan, yaitu C.

2. Menentukan rating kecocokan setiap alternatif pada setiap kriteria.

3. Membuat matriks keputusan berdasarkan kriteria, kemudian melakukan normalisasi matriks berdasarkan persamaan yang disesuaikan dengan jenis atribut (atribut benefit ataupun atribut cost) sehingga diperoleh matriks ternormalisasi $\mathrm{R}$.

Hasil akhir diperoleh dari proses perangkingan yaitu penjumlahan dari perkalian matriks ternormalisasi $\mathrm{R}$ dengan vector bobot sehingga diperoleh nilai terbesar yang dipilih sebagai alternatif terbaik (A) sebagai solusi.

\section{METODOLOGI PENELITIAN}

Tahapan penelitian yang dilakukan pada penelitian ini dapat dilihat pada gambar 3.1.

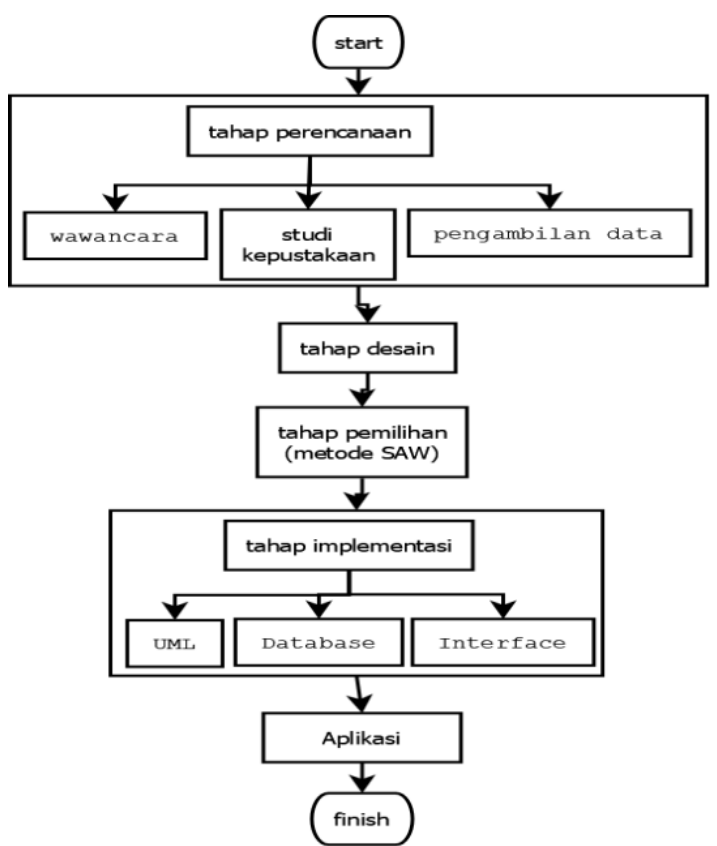

Gambar 3. 1 Tahapan Penelitian

Berdasarkan gambar 3.1 terdapat beberapa tahapan penelitian, masing-masing tahapan pada penelitian tersebut akan dibahas pada poin selanjutnya.

\subsection{Tahap Perencanaan}

Dalam penelitian ini, pengumpulan data merupakan tahapan terpenting yang harus dilakukan demi keberhasilan penelitian ini. Dimana hal ini sangat berkaitan dengan proses seleksi menentukan prioritas rencana kerja pembangunan desa (RKPDes) ini yang akan dimuat dalam aplikasi sistem pendukung keputusan yang berperan sebagai informasi.

\subsection{Tahap Desain}

Dalam Penyelesain penelitian tersebut berikut langkah yang harus dilakukan:

a. Menentukan Kriteria

Jenis Kriteria terlihat pada Tabel 1.

Table 1. Jenis Kriteria

\begin{tabular}{|l|l|l|}
\hline Kode & Kriteria & Kategori \\
\hline KT01 & Volume & Cost \\
\hline KT02 & Manfaat & Benefit \\
\hline KT03 & Waktu pelaksanaan & Cost \\
\hline KT04 & Anggaran & Cost \\
\hline
\end{tabular}

b. Menentukan rating kecocokan alternatif.

Table 2. Rating Kecocokan

\begin{tabular}{|l|l|l|}
\hline Kriteria & Keterangan & Nilai kepentingan \\
\hline Volume & $0 \mathrm{~s} / \mathrm{d} 100 \mathrm{~m}$ & 1 \\
\cline { 2 - 3 } & $101 \mathrm{~s} / \mathrm{d} 200 \mathrm{~m}$ & 0,9 \\
\cline { 2 - 3 } & $201 \mathrm{~s} / \mathrm{d} 300 \mathrm{~m}$ & 0,8 \\
\hline
\end{tabular}




\begin{tabular}{|c|c|c|}
\hline & $301 \mathrm{~s} / \mathrm{d} 400 \mathrm{~m}$ & 0,7 \\
\hline & $401 \mathrm{~s} / \mathrm{d} 500 \mathrm{~m}$ & 0,6 \\
\hline & $501 \mathrm{~s} / \mathrm{d} 600 \mathrm{~m}$ & 0,5 \\
\hline & $601 \mathrm{~s} / \mathrm{d} 700 \mathrm{~m}$ & 0,4 \\
\hline & $701 \mathrm{~s} / \mathrm{d} 800 \mathrm{~m}$ & 0,3 \\
\hline & $801 \mathrm{~s} / \mathrm{d} 900 \mathrm{~m}$ & 0,2 \\
\hline & $>900 \mathrm{~m}$ & 0,1 \\
\hline \multirow[t]{5}{*}{ Manfaat } & Masyarakat & 1 \\
\hline & Pertanian & 0,8 \\
\hline & Transportasi & 0,6 \\
\hline & Kesehatan & 0,4 \\
\hline & Keamanan & 0,2 \\
\hline \multirow{5}{*}{$\begin{array}{l}\text { Waktu } \\
\text { Pelaksanaan }\end{array}$} & $1 \mathrm{~s} / \mathrm{d} 2$ bulan & 1 \\
\hline & $2 \mathrm{~s} / \mathrm{d} 4$ bulan & 0.8 \\
\hline & $4 \mathrm{~s} / \mathrm{d} 6$ bulan & 0.6 \\
\hline & $6 \mathrm{~s} / \mathrm{d} 8$ bulan & 0.4 \\
\hline & $8 \mathrm{~s} / \mathrm{d} 12$ bulan & 0.2 \\
\hline \multirow[t]{5}{*}{ Anggaran } & $0 \mathrm{~s} / \mathrm{d} 100$ juta & 1 \\
\hline & $101 \mathrm{~s} / \mathrm{d} 200$ juta & 0,8 \\
\hline & 201 s/d 300 juta & 0,6 \\
\hline & $301 \mathrm{~s} / \mathrm{d} 400$ juta & 0,4 \\
\hline & $>400$ juta & 0,2 \\
\hline
\end{tabular}

\section{c. Menentukan Nilai Preferensi}

Bobot ini akan digunakan sebagai proses dalam pengambilan keputusan pada penentuan prioritas RKPDes yang dapat dilihat pada tabel 3.

Tabel 3. Nilai Preferensi

\begin{tabular}{|l|l|l|}
\hline Kode & Kriteria & Bobot \\
\hline KT01 & Volume & 4 \\
\hline KT02 & Manfaat & 5 \\
\hline KT03 & Waktu Pelaksanaan & 3 \\
\hline KT04 & Anggaran & 3 \\
\hline
\end{tabular}

\subsection{Tahap Pemilihan}

Dalam tahapan ini penentuan prioritas RKPDes dimana pemilihan ini bisa dilakukan dengan menggunakan inferensi Simple Additive Weighting yang sebelumnya telah ditentukan nilai kriteria dan bobot pada masing-masing kriteria. Setelah dilakukan proses normalisasi, selanjutnya akan dilakukan proses perkalian dengan bobot yang sudah ditentukan dan dihitung dengan rumus berdasarkan Persamaan 2.1 .
Setelah dilakukan normalisasi, untuk mendapatkan nilai vector dapat dilakukan proses menghitung nilai alternatif yang sudah ternormalisasi dengan menggunakan rumus berdasarkan Persamaan 2.2.

\subsection{Implementasi dan Solusi 3.4.1 Perancangan UML}

Use Case diagram dan Activity Diagram dapat dilihat seperti pada gambar 3.2 sampai gambar 3.6.

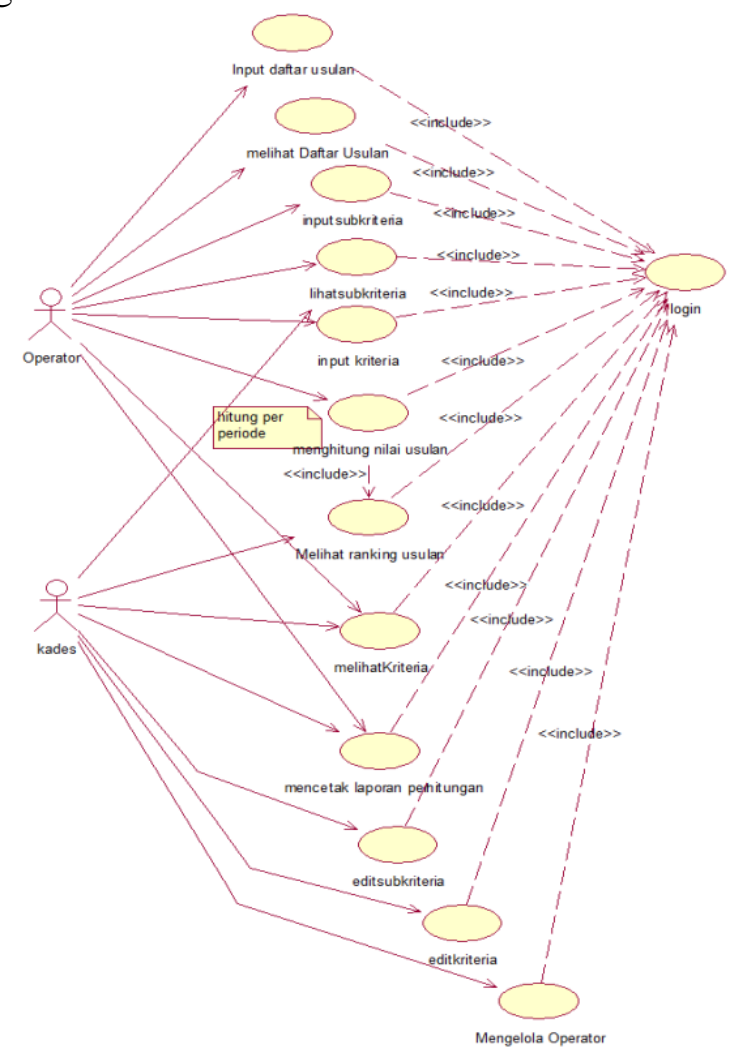

Gambar 3. 2 Use Case Diagram

Dalam rancangan Use Case pada penelitian ini, terdapat 2 aktor yang dapat mengakses sistem tersebut. Diantaranya aktor "operator" dengan akses input dan lihat Daftar Usulan, input dan lihat daftar kriteria serta subkriteria dan menghitung nilai Usulan untuk mendapatkan rekomendasi prioritas usulan. Kemudian aktor "kades" dengan akses edit dan lihat Daftar Kriteria serta subkriteria, mengelola data Operator, dan melihat rangking perhitungan dan mencetak laporan perhitungan. 


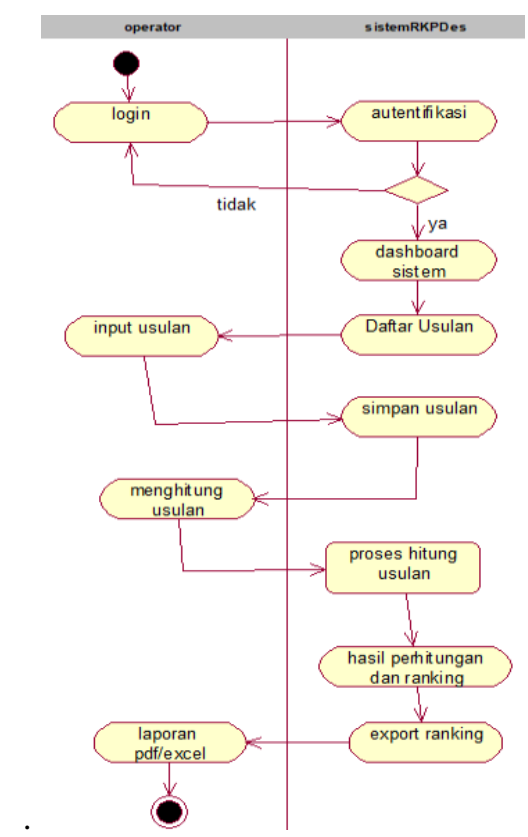

Gambar 3. 3 Activity Diagram Operator

Activity Diagram operator dimulai ketika operator mulai login pada sistem, kemudian operator akan diarahkan ke halaman dashboard setelah proses otentikasi, selanjutnya operator menginputkan Daftar Usulan dari menu Daftar Usulan untuk dihitung dengan persamaan SAW di sistem dan hasil perhitungan bisa diekspor sebagai laporan.

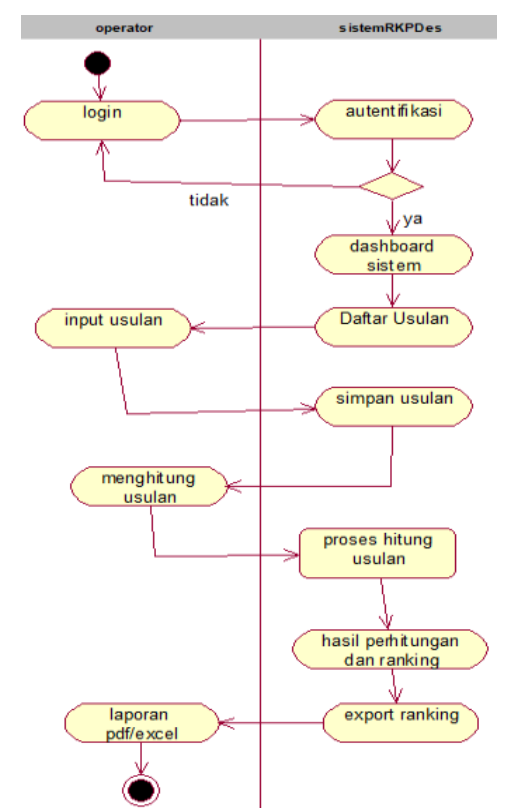

Gambar 3. 4 Activity Diagram Kades
Activity Diagram "Kades" dimulai ketika user login ke dalam sistem kemudian diarahkan ke halaman dashboard sistem setelah proses otentikasi, kemudian kades menginput tahun periode untuk melihat rangking prioritas Daftar Usulan untuk satu periode.

\subsubsection{Perancangan Database}

Terdapat beberapa tabel dalam rancangan database pada penelitian ini, diantaranya ada tabel T_USUALAN sebagai tabel data alternatif, kemudian tabel T_DT_USULAN sebagai tabel transaksi antara tabel alternatif dan nilai-nilai sub kriteria untuk masing-masing kriteria dalam tabel SUB_KRITERIA dan tabel KRITERIA untuk menyimpan data kriteria dan nilai preferensi.

Relasi tabel databse dapat dilihat pada Gambar 3. 6.

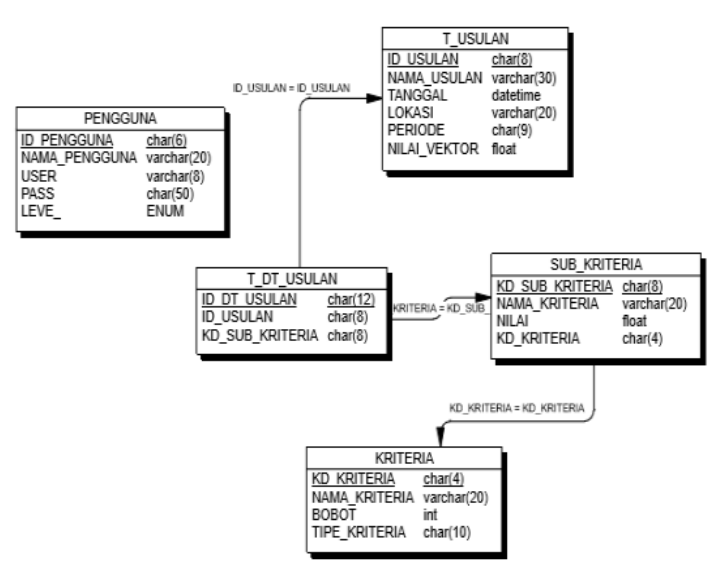

Gambar 3. 5 Relasi Database

\section{PEMBAHASAN}

\subsection{Perhitungan Metode SAW Manual}

Langkah pertama dalam perhitungan dengan metode SAW (Simple Additive Weighting) adalah menentukan data alternatif . seperti dalam tabel 4.1.

Tabel 4. 1 Nilai Awal

\begin{tabular}{|l|l|c|l|l|l|}
\hline \multirow{2}{*}{ No. } & \multicolumn{1}{|c|}{ Alternatif } & \multicolumn{4}{c|}{ Kriteria } \\
\cline { 3 - 6 } & & KT01 & KT02 & \multicolumn{1}{c|}{ KT03 } & KT04 \\
\hline 1. & rehab jalan desa rw 09 & $601-700$ & Masyarakat & $2-4$ bulan & $100-200$ \\
\hline 2. & Pembangunan rabat jalan desa Mekarwangi RW 07 & $301-400$ & Masyarakat & $2-4$ bulan & $0-100$ \\
\hline 3. & rabat jalan desa rw 08 & $301-400$ & Masyarakat & $2-4$ bulan & $0-100$ \\
\hline
\end{tabular}




\begin{tabular}{|l|l|l|l|l|l|}
\hline \multirow{2}{*}{ No. Alternatif } & \multicolumn{4}{c|}{ Kriteria } \\
\cline { 3 - 5 } & & \multicolumn{1}{|c|}{ KT01 } & \multicolumn{1}{|c|}{ KT02 } & \multicolumn{1}{c|}{ KT03 } & \multicolumn{1}{c|}{ KT04 } \\
\hline 4. & rabat jalan desa rw 06 & $401-500$ & Masyarakat & $2-4$ bulan & $0-100$ \\
\hline 5. & Pembangunan rabat jalan desa RW 07 & $301-400$ & Masyarakat & $2-4$ bulan & $101-200$ \\
\hline 6. & TPT rw 03 & $501-600$ & Pertanian & $1-2$ bulan & $201-300$ \\
\hline 7. & TPT rw 01 & $401-500$ & Masyarakat & $1-2$ bulan & $101-200$ \\
\hline 8. & TPT rw 02 & $401-500$ & Masyarakat & $1-2$ bulan & $101-200$ \\
\hline 9. & TPT rw 06 & $501-600$ & Masyarakat & $1-2$ bulan & $101-200$ \\
\hline 10. & Pengadaan Sarana Air bersih & $>900$ & Masyarakat & $1-2$ bulan & $101-200$ \\
\hline 11. & Pembangunan Jembatan & $0-100$ & Transportasi & $1-2$ bulan & $301-400$ \\
\hline 12. & Jalan Usaha Tani & $301-400$ & Pertanian & $1-2$ bulan & $101-200$ \\
\hline 13. & Pembangunan Drainese Jl Desa Rw 02 & $0-100$ & Pertanian & $1-2$ bulan & $0-100$ \\
\hline 14. & Jalan Lingkungan & $801-900$ & Masyarakat & $1-2$ bulan & $0-100$ \\
\hline 15. & Pengaspalan & $501-600$ & Transportasi & $1-2$ bulan & $101-200$ \\
\hline 16. & TPT saluran Irigasi & $501-600$ & Pertanian & $1-2$ bulan & $101-200$ \\
\hline 17. & Pemeliharaan jalan & $>900$ & Masyarakat & $1-2$ bulan & $0-100$ \\
\hline 18. & Pembangunan Draenase Jln Desa RW 01 & $0-100$ & Masyarakat & $1-2$ bulan & $0-100$ \\
\hline 19. & Pembangunan Draenase Jln Desa RW 03 & $0-100$ & Masyarakat & $1-2$ bulan & $0-100$ \\
\hline 20. & pembangunan draenae jn ds rw 2/p.ondin & $0-100$ & Masyarakat & $1-2$ bulan & $0-100$ \\
\hline
\end{tabular}

Langkah selanjutnya yaitu menentukan rating kecocokan dan bobot kriteria berdasarkan tabel nilai kepentingan yang telah ditentukan. Rating kecocokan dapat dilihat pada Tabel 4.2 .

Tabel 4. 2 Tabel Rating Kecocokan

\begin{tabular}{|l|l|l|l|l|}
\hline \multirow{2}{*}{ Alternatif } & \multicolumn{4}{|c|}{ Kriteria } \\
\cline { 2 - 5 } & KT01 & KT02 & KT03 & KT04 \\
\hline 1 & 0,4 & 1 & 0,8 & 0,8 \\
\hline 2 & 0,7 & 1 & 0,8 & 1 \\
\hline 3 & 0,7 & 1 & 0,8 & 1 \\
\hline 4 & 0,6 & 1 & 0,8 & 1 \\
\hline 5 & 0,7 & 1 & 0,8 & 0,8 \\
\hline 6 & 0,5 & 0,6 & 1 & 0,6 \\
\hline 7 & 0,6 & 1 & 1 & 0,8 \\
\hline 8 & 0,6 & 0,6 & 1 & 0,6 \\
\hline 9 & 0,5 & 1 & 1 & 0,8 \\
\hline 10 & 0,1 & 1 & 1 & 0,8 \\
\hline 11 & 1 & 0,8 & 1 & 0,4 \\
\hline 12 & 0,7 & 0,6 & 1 & 0,8 \\
\hline 13 & 0,7 & 0,6 & 1 & 0,8 \\
\hline 14 & 0,2 & 1 & 1 & 1 \\
\hline 15 & 0,5 & 0,8 & 1 & 0,8 \\
\hline 16 & 0,5 & 0,6 & 1 & 0,8 \\
\hline 17 & 0,1 & 1 & 1 & 1 \\
\hline 18 & 0,9 & 1 & 1 & 1 \\
\hline 19 & 0,9 & 1 & 1 & 1 \\
\hline 20 & 09 & 1 & 1 & 1 \\
\hline
\end{tabular}

Menentukan nilai minimal dan nilai maksimal berdasarkan tipe kriteria dapat dilihat pada tabel 4.3.

Tabel 4.3 Nilai Minimal/Maksimal

\begin{tabular}{|l|l|l|l|l|}
\hline \multirow{2}{*}{ Kriteria } & KT01 & KT02 & KT03 & KT04 \\
\cline { 2 - 5 } & Cost & Benefit & Cost & Cost \\
\hline Min/max & 0,1 & 1 & 0,8 & 0,4 \\
\hline
\end{tabular}

Normalisasi matriks $\mathrm{X}$ berdasarkan Rating Kecocokan seperti Persamaan 2.1.

Tabel 4.4 Normalisasi Matriks X

\begin{tabular}{|c|c|c|c|}
\hline Alternatif & Kriteria & $\begin{array}{l}\text { Rumus } \\
\text { Perhitungan }\end{array}$ & Hasil \\
\hline \multirow[t]{4}{*}{1} & KT01 & $0,1 / 0,4$ & 0,25 \\
\hline & KT02 & $1 / 1$ & 1 \\
\hline & KT03 & $0,8 / 0,8$ & 1 \\
\hline & KT04 & $0,4 / 0,8$ & 0,5 \\
\hline \multirow[t]{4}{*}{2} & KT01 & $0,1 / 0,7$ & 0,14 \\
\hline & KT02 & $1 / 1$ & 1 \\
\hline & KT03 & $0,8 / 0,8$ & 1 \\
\hline & KT04 & $0,4 / 1$ & 0,4 \\
\hline \multirow[t]{4}{*}{3} & KT01 & $0,1 / 0,7$ & 0,14 \\
\hline & KT02 & $1 / 1$ & 1 \\
\hline & KT03 & $0,8 / 0,8$ & 1 \\
\hline & KT04 & $0,4 / 1$ & 0,4 \\
\hline \multirow[t]{4}{*}{4} & KT01 & $0,1 / 0,6$ & 0,17 \\
\hline & KT02 & $1 / 1$ & 1 \\
\hline & KT03 & $0,8 / 0,8$ & 1 \\
\hline & KT04 & $0,4 / 1$ & 0,4 \\
\hline \multirow[t]{4}{*}{5} & KT01 & $0,1 / 0,7$ & 0,14 \\
\hline & KT02 & $1 / 1$ & 1 \\
\hline & KT03 & $0,8 / 0,8$ & 1 \\
\hline & KT04 & $0,4 / 0,8$ & 0,5 \\
\hline \multirow[t]{4}{*}{6} & KT01 & $0,1 / 0,5$ & 0,2 \\
\hline & KT02 & $0,6 / 1$ & 0,6 \\
\hline & KT03 & $0,8 / 1$ & 0,8 \\
\hline & KT04 & $0,4 / 0,6$ & 0,67 \\
\hline \multirow[t]{4}{*}{7} & KT01 & $0,1 / 0,6$ & 0,17 \\
\hline & KT02 & $1 / 1$ & 1 \\
\hline & KT03 & $0,8 / 1$ & 0,8 \\
\hline & KT04 & $0,4 / 0,8$ & 0,5 \\
\hline \multirow[t]{4}{*}{8} & KT01 & $0,1 / 0,6$ & 0,17 \\
\hline & KT02 & $0,6 / 1$ & 0,6 \\
\hline & KT03 & $0,8 / 1$ & 0,8 \\
\hline & KT04 & $0,4 / 0,6$ & 0,67 \\
\hline \multirow[t]{4}{*}{9} & KT01 & $0,1 / 0,5$ & 0,2 \\
\hline & KT02 & $1 / 1$ & 1 \\
\hline & KT03 & $0,8 / 1$ & 0,8 \\
\hline & KT04 & $0,4 / 0,8$ & 0,5 \\
\hline
\end{tabular}




\begin{tabular}{|c|c|c|c|}
\hline Alternatif & Kriteria & $\begin{array}{l}\text { Rumus } \\
\text { Perhitungan }\end{array}$ & Hasil \\
\hline \multirow[t]{4}{*}{10} & KT01 & $0,1 / 0,1$ & 1 \\
\hline & KT02 & $1 / 1$ & 1 \\
\hline & KT03 & $0,8 / 1$ & 0,8 \\
\hline & KT04 & $0,4 / 0,8$ & 0,5 \\
\hline \multirow[t]{4}{*}{11} & KT01 & $0,1 / 0,8$ & 0,1 \\
\hline & KT02 & $0,8 / 1$ & 0,8 \\
\hline & KT03 & $0,8 / 1$ & 0,8 \\
\hline & KT04 & $0,4 / 0,4$ & 1 \\
\hline \multirow[t]{4}{*}{12} & KT01 & $0,1 / 0,7$ & \begin{tabular}{|l|l|}
0,14 \\
\end{tabular} \\
\hline & KT02 & $0,6 / 1$ & \begin{tabular}{|l|}
0,6 \\
\end{tabular} \\
\hline & KT03 & $0,8 / 1$ & 0,8 \\
\hline & KT04 & $0,4 / 0,4$ & 0,5 \\
\hline \multirow[t]{4}{*}{13} & KT01 & $0,1 / 1$ & 0,1 \\
\hline & KT02 & $1 / 1$ & 1 \\
\hline & KT03 & $0,8 / 1$ & 0,8 \\
\hline & KT04 & $0,4 / 1$ & 0,5 \\
\hline \multirow[t]{4}{*}{14} & KT01 & $0,1 / 0,2$ & 0,5 \\
\hline & KT02 & $1 / 1$ & 1 \\
\hline & KT03 & $0,8 / 1$ & 0,8 \\
\hline & KT04 & $0,4 / 1$ & 0,4 \\
\hline \multirow[t]{4}{*}{15} & KT01 & $0,1 / 0,5$ & 0,2 \\
\hline & KT02 & $0,6 / 1$ & 0,6 \\
\hline & KT03 & $0,8 / 1$ & 0,8 \\
\hline & KT04 & $0,4 / 0,8$ & 0,5 \\
\hline \multirow[t]{4}{*}{16} & KT01 & $0,1 / 0,5$ & 1 \\
\hline & KT02 & $1 / 1$ & 1 \\
\hline & KT03 & $0,8 / 1$ & 0,8 \\
\hline & KT04 & $0,4 / 0,8$ & 0,5 \\
\hline \multirow[t]{4}{*}{17} & KT01 & $0,1 / 0,1$ & \begin{tabular}{|l|l|}
0,11 \\
\end{tabular} \\
\hline & KT02 & $1 / 1$ & 1 \\
\hline & KT03 & $0,8 / 1$ & 0,8 \\
\hline & KT04 & $0,4 / 1$ & 0,4 \\
\hline \multirow[t]{4}{*}{18} & KT01 & $0,1 / 0,9$ & \begin{tabular}{|l|l|}
0,11 \\
\end{tabular} \\
\hline & KT02 & $1 / 1$ & 1 \\
\hline & KT03 & $0,8 / 1$ & 0,8 \\
\hline & KT04 & $0,4 / 1$ & 0,4 \\
\hline \multirow[t]{4}{*}{19} & KT01 & $0,1 / 0,9$ & 0,11 \\
\hline & KT02 & $1 / 1$ & 1 \\
\hline & KT03 & $0,8 / 1$ & 0,8 \\
\hline & KT04 & $0,4 / 1$ & 0,4 \\
\hline \multirow[t]{4}{*}{20} & KT01 & $0,1 / 0,9$ & \begin{tabular}{|l|l|}
0,11 \\
\end{tabular} \\
\hline & KT02 & $1 / 1$ & 1 \\
\hline & KT03 & $0,8 / 1$ & 0,8 \\
\hline & KT04 & $0,4 / 1$ & 0,4 \\
\hline
\end{tabular}

Langkah selanjutnya adalah membuat matriks keputusan $(\mathrm{R})$ yang diperoleh dari hasil perhitungan normalisasi matriks $(\mathrm{X})$ yang akan dikalikan dengan bobot nilai di setiap kriteria (W). Kemudian hasil perkalian akan dijumlahkan dengan semua hasil perkalian bobot pada masing-masing kriteria seperti pada Persamaan 2.2.

Perkalian dan penjumlahan dengan bobot $\mathrm{W}$ dapat dinilai pada tabel 4.8 dengan ketentuan nilai $\mathrm{W}=\left[\begin{array}{llll}4 & 5 & 3 & 3\end{array}\right]$.

Tabel 4.5 Tabel Normalisasi Matriks R

\begin{tabular}{|l|l|l|l|}
\hline Alternatif & Kriteria & $\begin{array}{l}\text { Rumus } \\
\text { Perhitungan }\end{array}$ & Hasil \\
\hline
\end{tabular}

\begin{tabular}{|c|c|c|c|}
\hline Alternatif & Kriteria & \begin{tabular}{|l|} 
Rumus \\
Perhitungan
\end{tabular} & Hasil \\
\hline \multirow[t]{5}{*}{1} & KT01 & $4 \times 0,25$ & 1 \\
\hline & KT02 & $5 \times 1$ & 5 \\
\hline & KT03 & $3 \times 1$ & 3 \\
\hline & KT04 & $3 \times 0,5$ & 1,5 \\
\hline & & Total & 10,5 \\
\hline \multirow[t]{5}{*}{2} & KT01 & $4 \times 0,14$ & 0,56 \\
\hline & KT02 & $5 \times 1$ & 5 \\
\hline & KT03 & $3 \times 1$ & 3 \\
\hline & KT04 & $3 \times 0,4$ & 1,2 \\
\hline & & Total & 9,76 \\
\hline \multirow[t]{5}{*}{3} & KT01 & $4 \times 0,14$ & 0,56 \\
\hline & KT02 & $5 \times 1$ & 5 \\
\hline & KT03 & $3 \times 1$ & 3 \\
\hline & KT04 & $3 \times 0,4$ & 1,2 \\
\hline & & Total & 9,76 \\
\hline \multirow[t]{5}{*}{4} & KT01 & $4 \times 0,17$ & 0,68 \\
\hline & KT02 & $5 \times 1$ & 5 \\
\hline & KT03 & $3 \times 1$ & 3 \\
\hline & KT04 & $3 \times 0,4$ & 1,2 \\
\hline & & Total & 9,88 \\
\hline \multirow[t]{5}{*}{5} & KT01 & $4 \times 0,14$ & 0,56 \\
\hline & KT02 & $5 \times 1$ & 5 \\
\hline & KT03 & $3 \times 1$ & 3 \\
\hline & KT04 & $3 \times 0,5$ & 1,5 \\
\hline & & Total & 10,06 \\
\hline \multirow[t]{5}{*}{6} & KT01 & $4 \times 0,2$ & 0,8 \\
\hline & KT02 & $5 \times 0,6$ & 3 \\
\hline & KT03 & $3 \times 0,8$ & 2,4 \\
\hline & KT04 & $3 \times 0,67$ & 2,01 \\
\hline & & Total & 8,21 \\
\hline \multirow[t]{5}{*}{7} & KT01 & $4 \times 0,17$ & 0,68 \\
\hline & KT02 & $5 \times 1$ & 5 \\
\hline & KT03 & $3 \times 0,8$ & 2,4 \\
\hline & KT04 & $3 \times 0,5$ & 1,5 \\
\hline & & Total & 9,58 \\
\hline \multirow[t]{5}{*}{8} & KT01 & $4 \times 0,17$ & 0,68 \\
\hline & KT02 & $5 \times 0,6$ & 3 \\
\hline & KT03 & $3 \times 0,8$ & 2,4 \\
\hline & KT04 & $3 \times 0,67$ & 2,01 \\
\hline & & Total & 8,09 \\
\hline \multirow[t]{5}{*}{9} & KT01 & $4 \times 0,2$ & 0,8 \\
\hline & KT02 & $5 \times 1$ & 5 \\
\hline & KT03 & $3 \times 0,8$ & 2,4 \\
\hline & KT04 & $3 \times 0,5$ & 1,5 \\
\hline & & Total & 9,7 \\
\hline \multirow[t]{5}{*}{10} & KT01 & $4 \times 1$ & 4 \\
\hline & KT02 & $5 \times 1$ & 5 \\
\hline & KT03 & $3 \times 0,8$ & 2,4 \\
\hline & KT04 & $3 \times 0,5$ & 1,5 \\
\hline & & Total & 12,9 \\
\hline \multirow[t]{5}{*}{11} & KT01 & $4 \times 0,1$ & 0,4 \\
\hline & KT02 & $5 \times 0,8$ & 4 \\
\hline & KT03 & $3 \times 0,8$ & 2,4 \\
\hline & KT04 & $3 \times 1$ & 3 \\
\hline & & Total & 9,8 \\
\hline \multirow[t]{5}{*}{12} & KT01 & $4 \times 0,14$ & 0,56 \\
\hline & KT02 & $5 \times 0,6$ & 3 \\
\hline & KT03 & $3 \times 0,8$ & 2,4 \\
\hline & KT04 & $3 \times 0,5$ & 1,5 \\
\hline & & Total & 7,46 \\
\hline \multirow[t]{2}{*}{13} & KT01 & $4 \times 0,1$ & 0,4 \\
\hline & KT02 & $5 \times 1$ & 5 \\
\hline
\end{tabular}




\begin{tabular}{|c|c|c|c|}
\hline Alternatif & Kriteria & $\begin{array}{l}\text { Rumus } \\
\text { Perhitungan }\end{array}$ & Hasil \\
\hline & KT03 & $3 \times 0,8$ & 2,4 \\
\hline & KT04 & $3 \times 0,4$ & 1,2 \\
\hline & \multicolumn{2}{|r|}{ Total } & 9 \\
\hline \multirow[t]{5}{*}{14} & KT01 & $4 \times 0,5$ & 2 \\
\hline & KT02 & $5 \times 1$ & 5 \\
\hline & KT03 & $4 \times 0,8$ & 2,4 \\
\hline & KT04 & $3 \times 0,4$ & 1,2 \\
\hline & \multicolumn{2}{|r|}{ Total } & 10,6 \\
\hline \multirow[t]{5}{*}{15} & KT01 & $4 \times 0,2$ & 0,8 \\
\hline & KT02 & $5 \times 0,8$ & 4 \\
\hline & KT03 & $3 \times 0,8$ & 2,4 \\
\hline & KT04 & $3 \times 0,5$ & 1,5 \\
\hline & \multicolumn{2}{|r|}{ Total } & 8,7 \\
\hline \multirow[t]{5}{*}{16} & KT01 & $4 \times 0,2$ & 0,8 \\
\hline & KT02 & $5 \times 0,6$ & 3 \\
\hline & KT03 & $3 \times 0,8$ & 2,4 \\
\hline & KT04 & $3 \times 0,5$ & 1,5 \\
\hline & \multicolumn{2}{|r|}{ Total } & 7,7 \\
\hline \multirow[t]{5}{*}{17} & KT01 & $4 \times 1$ & 4 \\
\hline & KT02 & $5 \times 1$ & 5 \\
\hline & KT03 & $3 \times 0,8$ & 2,4 \\
\hline & KT04 & $3 \times 0,4$ & 1,2 \\
\hline & \multicolumn{2}{|r|}{ Total } & 12,6 \\
\hline \multirow[t]{3}{*}{18} & KT01 & $4 \times 0,11$ & 0,44 \\
\hline & KT02 & $5 \times 1$ & 5 \\
\hline & KT03 & $3 \times 0,8$ & 2,4 \\
\hline
\end{tabular}

\begin{tabular}{|c|c|c|c|}
\hline Alternatif & Kriteria & $\begin{array}{l}\text { Rumus } \\
\text { Perhitungan }\end{array}$ & Hasil \\
\hline & KT04 & $3 \times 0,4$ & 1,2 \\
\hline & \multicolumn{2}{|r|}{ Total } & 9,04 \\
\hline \multirow[t]{5}{*}{19} & KT01 & $4 \times 0,11$ & 0,44 \\
\hline & KT02 & $5 \times 1$ & 5 \\
\hline & KT03 & $3 \times 0,8$ & 2,4 \\
\hline & KT04 & $3 \times 0,4$ & 1,2 \\
\hline & \multicolumn{2}{|r|}{ Total } & $\mathbf{9 , 0 4}$ \\
\hline \multirow[t]{5}{*}{20} & KT01 & $4 \times 0,11$ & 0,44 \\
\hline & KT02 & $5 \times 1$ & 5 \\
\hline & KT03 & $3 \times 0,8$ & 2,4 \\
\hline & KT04 & $3 \times 0,4$ & 1,2 \\
\hline & \multicolumn{2}{|r|}{ Total } & $\mathbf{9 , 0 4}$ \\
\hline
\end{tabular}

Dari hasil perhitungan pada tabel 4.5, maka dapat dihasilkan beberapa usulan dengan 12 nilai vektor tertinggi yang akan menjadi rekomendasi usulan agar dimusyawarahkan untuk direalisasikan dan dibandingkan dengan 12 (dua belas) data usulan RKPDes desa Ciburuy yang sudah direalisasikan pada tahun 2017. Tabel perbandingan hasil perhitungan metode SAW dengan 12 Usulan RKPDes 2017 dapat dilihat pada tabel 4.6.

Tabel 4. 6 Tabel Perbandingan

\begin{tabular}{|c|l|c|l|c|}
\hline \multirow{2}{*}{ Ranking } & \multicolumn{2}{|c|}{ Hasil perhitungan SAW } & \multicolumn{1}{c|}{ Data RKPDes tahun 2017 } & Keterangan \\
\cline { 2 - 5 } & \multicolumn{1}{|c|}{ Daftar Usulan } & Dektor & & \\
\hline 1 & Pengadaan sarana air bersih & 12,90 & Pengadaan sarana air bersih & sesuai \\
\hline 2 & Pemeliharaan jalan & 12,60 & Pemeliharaan jalan & Sesuai \\
\hline 3 & Jalan Lingkungan & 10,60 & Jalan Lingkungan & Sesuai \\
\hline 4 & Rehab jalan desa rw 09 & 10,50 & Rehab jalan desa rw 09 & Sesuai \\
\hline 5 & Pembangunan rabat jalan desa RW 07 & 10,06 & Pembangunan rabat jalan desa RW 07 & Sesuai \\
\hline 6 & Rabat jalan desa rw 06 & 9,88 & Rabat jalan desa rw 06 & Sesuai \\
\hline 7 & Pembangunan Jembatan & 9,80 & Pembangunan Jembatan & Sesuai \\
\hline 8 & Rabat jalan desa rw 08 & 9,76 & Rabat jalan desa rw 08 & Sesuai \\
\hline 9 & Pembangunan rabat jalan desa & 9,76 & $\begin{array}{l}\text { Pembangunan rabat jalan desa } \\
\text { Mekarwangi RW 07 }\end{array}$ & Sesuai \\
\hline 10 & Mekarwangi RW 07 & 9,70 & Pembangunan Drainase jln Desa RW 02 & Tidak sesuai \\
\hline 11 & TPT RW 06 & 9,57 & Pembangunan Drainase jln Desa RW 01 & Tidak sesuai \\
\hline 12 & TPT Rw 03 & 9,04 & $\begin{array}{l}\text { Pembangunan Drainase jln ds RW } \\
\text { 2/p.ondin }\end{array}$ & Tidak sesuai \\
\hline
\end{tabular}

Berdasarkan 12 data usulan dalam tabel perbandingan di atas, terdapat 9 (sembilan) usulan hasil penelitian menggunakan metode SAW yang sesuai dengan data usulan RKPDes tahun 2017. Untuk mendapatkan nilai hasil presentase dapat dilakukan dengan persaman 4.1.

$$
\begin{aligned}
\text { Persentase Kebenaran } & =\frac{\text { sesuai }}{\text { total }} \times 100 \% \\
& =\frac{9}{12} \times 100 \% \\
& =75 \%
\end{aligned}
$$

\section{KESIMPULAN}

Berdasarkan hasil penelitian yang telah dilakukan maka dapat disimpulkan bahwa Sistem dapat bekerja dengan menggunakan metode Simple Additive Weighting untuk menghitung nilai bobot akhir pada masingmasing alternatif yang sudah terdaftar dengan hasil presentase kebenaran sebesar $75 \%$ dari data yang ada. 


\section{DAFTAR PUSTAKA}

Bahari, A. T., \& dkk. (2017). Sistem Pendukung Keputusan Penentuan Lokasi Bimbingan Belajar Dengan Metode Weight Product (WP) Berbasis WEBGIS.http://journal.stthmedan.ac.id.

Harigunna, T., \& Arinta, O. (2017). Penentuan Prioritas Program Kerja Pada Anggaran Pendapatan dan Belanja Desa Menggunakan Metode Analytical Hierarchy Process . Retrieved 2018, from citisee.amikompurokerto: http://citisee.amikompurwokerto.ac.id/a ssets/proceedings/2017/SI26.pdf

Karim, J. (2018). Sistem Pendukung Keputusan Penentuan Prioritas Pembangunan Menggunakan Metode Promothee Pada Desa Ayula Kecamatan Randangan Kabupaten Pohuwato Provinsi Gorontalo. ILKOM Jurnal Ilmiah Volume 10, 86.

Muhammad, M., Safriadi, N., \& dkk. (2017). Implementasi Metode Simple Additive Weighting (SAW) Pada Sistem Pendukung Keputusan Dalam Menentukan Prioritas Perbaikan Jalan. Jurnal Sistem dan Teknologi Informasi (JUSTIN).

Nilogiri, A., \& Arifianto, D. (2016). Sistem Pendukung Keputusan Prioritas Lokasi Perbaikan Jalan. JUSTINDO.

RI, D. (2004). Undang-Undang Republik Indonesia Nomor 32 Tahun 2004 Tentang Pemerintahan Daerah. Retrieved from Dpr.go.id: http://www.dpr.go.id/dokjdih/document /uu/33.pdf
Riadi, M. (2013, September 18). Sistem Pendukung Keputusan (SPK). Retrieved from kajianpustaka.com: https://www.kajianpustaka.com/2013/0 9/sistem-pendukung-keputusanspk.html

Rufiqo, R. (2009). Sistem Pendukung Keputusan Menentukan Lokasi Pembagunan Perumahan Dengan Metode Analytical Hierarchy Process (AHP), repository.uin-suska.ac.id.

Saputri, A. D., \& Oktafiano. (2017). Sistem Pendukung Keputusan Untuk Menentukan Lokasi Perumahan di Kabupaten Pringsewu Menggunakan Metode Weighted Product. ojs.stmikpringsewu.ac.id.

Satria, A. (2015). Teori Pembangunan : Definisi Pembangunan Masyarakat Serta Tujuan Pembangunan Yang Dilakukan Dalam Proses Pembangunan. Retrieved from materibelajar.id:

http://www.materibelajar.id/2016/01/te ori-pembangunan-definisipembangunan.html\#

Sumarna, A. (2016, 7 18). RKP Desa (Rencana Kerja Pemerintah Desa. Retrieved from keuangandesa.info: https://www.keuangandesa.info/2016/0 7/rkp-desa-rencana-kerja-pemerintahdesa.html

Turban, E., \& Liang, T.-P. (2005). Decision Support Systems and Intelligent Systems Edisi Bahasa Indonesia. Yogyakarta: Andi. 